\title{
Las palabras que esculpen los cuerpos
}

\author{
Mayra Alejandra Flores Muñoz ${ }^{1}$
}

Resumen

LAS CARACTERÍSTICAS QUE DEFINEN LO FEMENINO SON CONSTRUCCIONES SOCIALES, SOMOS LOS SERES HUMANOS QUIENES LLENAMOS DE SIGNIFICAdO LOS CUERPOS. EN EL PRESENTE TRABAJO QUEREMOS HACER UNA REFLEXIÓN TEÓRICA DE LAS REPRESENTACIONES TOMANDO COMO CASO DE ESTUdIO LAS CATEGORÍAS CON QUE DEFINIMOS LA FEMINIDAD EN DIFERENTES GENERACIONES Y CONTEXTOS HISTÓRICOS DE LA CIUDAD DE QUITO, Y CóMO ÉSTA HA ESTADO O NO LIGADA A LA MATERNIDAD ELECTIVA.

Palabras ClaVe: REPRESENTACión - PODER, GÉNERO - IDENTIFICACIÓN - FEMINIDAD - MATERNIDAD.

Abstract

THE CHARACTERISTICS WHICH DEFINE THE FEMININE ARE SOCIAL CONSTRUCTIONS; WE ARE THE HUMAN BEINGS WHO FILL THE BODIES WITH MEANING. IN THE PRESENT WORK WE ATTEMPT A THEORETICAL ANALYSIS OF FEMININE DEPICTIONS, TAKING AS A CASE STUDY THE CATEGORIES WITHIN WHICH WE DEFINE FEMININITY IN DIFFERENT GENERATIONS AND HISTORICAL CONTEXTS OF THE CITY OF QUITO, AND HOW FEMININITY HAS BEEN OR NOT LINKED TO ELECTIVE MOTHERHOOD.

KEY WORDS: DEPICTION - POWER - GENDER - IDENTIFICATION - FEMININITY - MOTHERHOOD.

1 Antropóloga con mención en Antropología Sociocultural. Funcionaria en SENPLADES- Zona 2, Tena.

Correo electrónico:mafm_89@hotmail.com/mafmunoz89@gmail.com 


\section{Introducción}

— $\mathrm{n}$ Ecuador, el siglo XX está caracterizado en principio por la revolución liberal que significó un cambio de instituciones, de ejercicio del poder estatal, de concepción de la ciudadanía, así como de organización del trabajo, de la producción y de la familia.

La historia de las mujeres en el Ecuador, su inclusión en la esfera pública, su acceso a derechos legales y políticos, así como también la creciente apertura a puestos laborales tienen un interesante recorrido; ya que, aunque el Estado se haya esforzado por promover una homologación de la identificación femenina con la maternidad, otros tipos de participación política, legal, intelectual, de ejercicio de libertad individual y de identificaciones desde las mujeres se han construido a lo largo del siglo XX.

Cabe resaltar que solo en la urbe adquiere sentido hablar de una separación histórica de las esferas públicas y privadas, que además están ligadas a una forma de división sexual del trabajo. Las mujeres situadas tradicionalmente en lo doméstico ${ }^{2}$, con el anonimato que ganan a partir del crecimiento urbano ${ }^{3}$, la modernización del aparato estatal y el creciente comercio que abrió plazas de trabajo para mujeres tanto de sectores medios como populares, la pérdida de poder de la estructura familiar como reguladora de la vida a partir de la secularización del estado y la creciente dependencia de espacios de socialización y resguardo de la infancia fuera del hogar, acceden a nuevos espacios de acción antes restringidos -específicos del mundo urbano.

En el marco de esa transgresión del rol fundamental de la mujer como madre de familia, en medio de la transformación de los sistemas de referencias tradicionales, nuevas representaciones emergieron para dar sentido a las existencias y a la colectividad.

En este sentido sostenemos que el lenguaje, la construcción de las palabras, la semántica y los análisis de los discursos permiten mirar la estructura social sin oponerse al proceso histórico donde se renuevan o se adaptan. Las representaciones son síntesis de sentido en un contexto específico, según Mato (2000), siendo así ésta es una ruta a la interpretación de las culturas.

En el presente artículo queremos hacer una reflexión sobre el concepto de "representación" como vía teórica para el análisis del cambio cultural. Para lo cual utilizaremos las representaciones sobre la feminidad construidas en torno la planificación de la maternidad en dos generaciones de quiteñas, con el fin de mirar cómo se generan desde una estructura social y un proceso histórico de disputas de poder.

A este efecto, cabe señalar que nos basaremos en una entrevista grupa ${ }^{5}$ realizada a tres generaciones de mujeres de una familia quiteña, donde primordialmente a partir del diálogo de la generación más antigua y la más joven, se contrasta la representación de la maternidad planificada y no planificada, que emergen en un tejido cultural y momentos históricos diferentes.

En la primera parte revisaremos qué entendemos por representación y cómo ésta se relaciona con la cultura, más adelante haremos un análisis de la identificación, y finalmente se hará una reflexión final de las representaciones en la estructura y momento histórico actual.

\section{Concatenación de sentidos}

Los seres humanos aprehendemos el mundo almacenando, por así decirlo, un sistema de referencias de las experiencias vividas a través de conceptos, esta es la principal función de las

2 Como menciona Goetschel (2001) era mal visto el que una señorita intentase siquiera optar por una vida independiente.

3 Las cuestiones de pudor y resguardo "del qué dirán” de la sociedad quiteña de principios de siglo con la acelerada expansión urbana de los años sesenta fue perdiendo peso en el curso y decisiones de las individuas.

4 Colegios, talleres, escuelas, guarderías, etc. La escuela como segundo espacio de socialización introdujo a las mujeres, y a la sociedad en general, a un sistema basado en méritos, exámenes, competitividad, restricciones, disciplina, organización, niveles, pero también fracasos, rechazos, normalidad y anormalidad, incompetencia, etc. Lo más importante, introduce en la rutina de las mujeres una preocupación por el yo.

5 Que permita develar los quiebres, los cambios, acuerdos y desacuerdos entre una generación y otra, en una misma familia, con un mismo espectro de valores. 
palabras: clasificar. Construimos una representación del mundo, de los otros, de un objeto, de cualquier cosa al conectar una imagen, idea o percepción de éstos en nuestras mentes y asignarles un nombre (que no es más que un conjunto de sonidos o letras), que utilizamos para referirnos a ese cuerpo, y poder comunicar a través de esta palabra algo más; una idea, una asociación, una orden, un sentimiento, etc.

La representación es justamente la práctica por la cual la realidad concreta se encuentra con el sentido, en palabras de Hall (2000), es por la cual se otorga significado a través del lenguaje a las experiencias, a las decisiones, prácticas sociales y rutinas. La cultura nos ofrece respuestas que permiten cubrir nuestra necesidad de pensar qué hacer y por qué hacerlo.

El uso de un lenguaje común nos permite entender las experiencias de manera similar, así llegamos a consensos acerca de la clasificación de las cosas y su organización, es decir, conformamos un sistema conceptual por medio del cual intercambiamos significado. Esto, sin embargo, es un acto complejo; ya que al nombrar se construye una estructura de las relaciones que mantenemos - como corporeidad que somos en principio- con un entorno (el mundo, las personas, las cosas, todo).

Los signos ${ }^{6}$ como miembros de un sistema están definidos en relación a los otros miembros del sistema, el significado es algo relacional, una relación de diferencia o semejanza entre las cosas que la mente aprehende de la realidad, las clasificaciones y asociaciones que otorga (Barthes, 2000).

Es así, que nada en la naturaleza dictamina que la relación entre los sexos sea de oposición y no de pares, es más, nada determina que esos sexos sean dos y no tres o cuatro ${ }^{7}$, así como tampoco que uno $\mathrm{u}$ otro tenga que dar tal o cual cuidado a la progenie, pero es así como clasifica nuestra cultura la diferencia de los cuerpos, igual que macho-hembra, hombre-mujer, paternidadmaternidad; y que además al ser una relación y estar en un contexto social denota jerarquías y poder.

Por lo tanto, la micropolítica, las relaciones interpersonales, las prácticas y las rutinas se sitúan en principio en un cuerpo atravesado por la cultura e historia, que lo nombran, lo identifican, es decir lo representan.

\section{Identificación: los cuerpos que se nombran}

El vínculo entre lo social y lo individual se va tejiendo desde nuestro nacimiento, incluso, cuando aún no hemos adquirido o entendido a cabalidad las reglas de nuestro universo lingüístico y semántico estamos inmersos en actos comunicativos. Por ejemplo, cuando somos infantes y nos visten de niño o niña, nuestros progenitores generan a partir de un código de vestimenta -una representación, en este caso como imagen- un mensaje que comunica el sexo del bebé.

Cuando una persona adopta una imagen (femenina por ejemplo), se inserta en una suerte de relaciones prefabricadas, está comunicando a través de símbolos el rol que ocupa en una estructura social, que, aunque está dada en su mayoría, no deja de regenerarse y reconstruirse a lo largo de la vida del individuo o individua.

"La cuestión religiosa a mí me chocó terriblemente. Terriblemente y mi mamá decía no hagas caso, pero yo empecé desde muy chiquita, desde muy niña a cuestionar por ejemplo los dogmas, ya" (abuela, entrevista grupal, 2013).

6 El signo mujer, complejo, cargado de significado, definido con las características físicas que imaginamos cuando lo evocamos y situado en la especificidad de conjunto social, se construye y reconstruye a lo largo de la vida de las individuas, de las historias, de las conversaciones, de lo cotidiano.

7 ¿Qué pasa con los hermafroditas o intersexuales? ¿Y la gente transexual y asexual? ¿Acaso nuestra sociedad no tiene otro sistema de referencia para estas personas que la anormalidad? 
En nuestra sociedad, los y las infantes no entienden el sistema que reproducen, su mundo es de los afectos, las sensaciones y sensibilidad, no conocen qué significa ser niña y qué significa ser niño, no nacen con prejuicios, son los adultos los que generan los rechazos, la discriminación o aceptación, las categorías con que se juzga a otros.

"Y en mi época se fijaban mucho en los apellidos y...o sea, por ejemplo, si yo traía un morenito, lo primero que preguntaban era ¿qué apellido es? Entonces descartado porque no es...” (Ibid.).

La infancia asume lo que su núcleo familiar afirma como verdad, y que implanta en sus conductas a partir de diversas formas de disciplinamiento, como el castigo físico, el chantaje emocional, enojo, etc. que lentamente van reprimiendo la sensibilidad por racionalidad.

"Claro, yo soy de la época en que las mamás pegaban a los hijos porque la letra con sangre entra, y pegándoles para que aprendan" (Ibid.).

La infancia por lo general está marcada por las actividades y roles reproducidos en base al género, que por lo general designan lo doméstico como lugar legítimo para las mujeres, y que a su vez sitúan los conocimientos generados en dicho espacio a detrimento de un opuesto dominante -lo masculino, cubriendo de pesar y obligación las tareas, entorpeciendo, por lo general, la apropiación dichosa de los saberes maternos.

"Mi mamá también escribía, mi mamá tenía para cada hijo una libretita donde iba anotando, más que anotaciones eran impresiones, y mi mamá leía mucho, y yo decía mi mamá podía haber estado... en vez de estar atendiendo a los doce hijos, podía estar leyendo, o podía haber estado haciendo cosas que a ella le gustaban más. Entonces yo decía nunca me casaré, yo será solterona" (Ibid.).

¿La división sexual del trabajo es el origen de la igualdad maternidad-feminidad, mujersumisión?; más bien parecería que es la asociación que hacemos de estos términos, es la relación que establecemos entre unos y otros lo que conforma una estructura social, una cultura, que valora y glorifica un tipo de trabajo por sobre otro, ejerce la dominación y asigna un lugar "natural" a los sexos.

Las relaciones que establecemos los seres humanos en general, desde un posicionamiento (como el asignado al género), se ven condicionadas por las alternativas que una u otra estructura presenta; "pero ve, en mi época éramos más o menos todas dedicadas al estudio, de 16 que nos graduamos solo una fue a la universidad" (Ibid.).

Por este motivo, cuando un rol alternativo ha emergido, las relaciones que no han sido "prefabricadas" producen malestar, cuestionamiento y reconfiguración en la sociedad (como la solterona a principios de siglo XX, la pugna por las identidades sexuales un siglo después, la chulla quiteña, etc.).

Es así que Tubert (2004) dice que la mujer que no es madre perturba de alguna manera las relaciones instituidas entre hombres y mujeres, atenta contra la organización establecida por sexos, contra la clasificación y caracterización compleja que subyace a las palabras que nombran los cuerpos: “...tú (se dirige a su nieta) todavía aceptas que lo más grande que puede tener la mujer es la maternidad" (abuela, entrevista grupal, 2013).

Es importante señalar que esta oración está enmarcada en un contexto discursivo de lo que "ser mujer" significa a partir de la diferencia entre generaciones -la abuela que interpela a la nieta, quien se encontraba expresando su opinión acerca de la feminidad y la maternidad.

El momento en que la abuela representa por medio de estas palabras, se hace portadora de la voz de su época ${ }^{8}$, que por un lado, tiene límites concretos (no poder acceder a una universidad, a

8 “...era la época ¿no? Uno se casaba para tener hijos y ta, ta, ta” (abuela). 
anticonceptivos, a propiedad privada, etc.), impuestos en su mayoría por el sistema económico, por la dificultad de adquisición material que se traduce a la final en la insatisfacción de las necesidades para la supervivencia; y por el otro lado, conceptos, ideas con las que se entienden esas realidades, que posicionan en sociedad a la persona, y que expresan un ejercicio de poder ${ }^{9}$ o resistencia.

"No se podría obligar directamente a la mujer a dar a luz: todo cuanto se puede hacer es encerrarla en situaciones donde la maternidad sea para ella la única salida; la ley o las costumbres le imponen el matrimonio, se prohíben los procedimientos anticonceptivos y el aborto, se prohíbe el divorcio" (Beauvoir, 1999: 59).

Subyacente a la proposición de la abuela hay otro modelo de "lo más grande que le puede suceder a la mujer", enmarcado en otros ideales de realización, que responden al éxito profesional, acumulación material, fama, etc. ante los cuales la nieta "todavía" acepta la maternidad como plenitud del ser mujer, aunque para ella misma (la abuela) ser madre surgió en un contexto que le hizo percibirla como un acontecimiento "trágico"10 e inevitable.

Es así, que parece haber una doble resistencia, la primera, contra el sistema que no le permitió elección cuando tuvo sus primeros hijos, y la segunda, al sistema actual que, "permitiendo" la elección, sujeta a la mujer a un sistema productivo privándola del disfrute de la maternidad. ¿Puede la abuela imaginar un ejercicio de maternidad alternativo? No lo sabemos, y ella no hace el esfuerzo porque esto no le corresponde, quizá ella no está en ese periodo vital que la impulsa a proponer soluciones, como sí lo está la nieta, que efusivamente responde:

"Nieta: es que no sé si soy la excepción...creo que si se tiene que reivindicar justamente esa palabra [maternidad]. O sea yo creo que antes era obligatorio ser madre, no sé digamos que toda esta transformación que ha tenido el sistema...

Abuela: ninguna maravilla ¿no? Porque era obligatorio.

Nieta: te permite elegir, quiero o no ser madre

Madre: claro la mayoría llegaban a sexto curso y tenían que casarse y formar su familia. Y muy pocas amas de casa trabajaban pues" (Ibid.).

¿Quién a quién permite elegir? ¿El sistema al individuo? Ciertamente ya no se ejerce presión social (si entendemos a ésta como comentarios, burlas o desapruebo) en ciertos grupos clase media-urbana para casarse, tener hijos, formar una familia, etc. Por el contrario, hay incentivos para retrasar la maternidad, hasta alcanzar posicionamiento social y económico ${ }^{11}$.

"Nieta: o sea eso, claro, es bueno. Pero siento también de cierta manera que, que no sé... que se ha roto como un vínculo espiritual con la feminidad también, y que yo diga eso es bastante raro. Abuela: bastante raro a tu edad que digas eso" (Ibid.).

Con la secularización de la vida pública - por añadidura de la privada también- y la pérdida del dominio eclesiástico sobre los deberes e ideales, se erosionó paulatinamente la imagen de la feminidad maternal y virginal en el dogma católico, ese llamado divino que destinaba a la mujer al hogar, la familia, lo doméstico, la prudencia, el silencio, el sacrificio, y finalmente la gloria celestial.

9 No se podría obligar directamente a la mujer a dar a luz: todo cuanto se puede hacer es encerrarla en situaciones donde la maternidad sea para ella la única salida; la ley o las costumbres le imponen el matrimonio, se prohíben los procedimientos anticonceptivos y el aborto, se prohíbe el divorcio (Beauvoir, 1999: 59).

10 En sus propias palabras, (abuela, historia de vida, 2013).

11 No obstante, aún hay presión en los grupos etarios que llegan a los 30-40 sin hijos. 
Se puede pensar el marianismo como la expresión de una representación hegemónica que es más o menos utilizado en la construcción de la identidad y que guarda las características ${ }^{12}$ que Stevens (1973) otorga. Por medio de la religión y la ciencia se disputaron sentidos, creencias, conductas y elecciones, generando incertidumbre y cambio en las concepciones del mundo y de las personas. Quizá porque desde la fe se respondían los por qué y para qué de la existencia ${ }^{13}$. "Todo era malo, todo era pecado, todo era a escondidas, de manera que vinieron los hijos, nacieron los hijos pues y no había más” (abuela, entrevista grupal, 2013).

Los valores católicos y el ideal de la virgen María, aunque pueden seguir presentándose y reafirmándose de diversas formas en ciertos grupos sociales, han perdido la hegemonía que tenían a principios de siglo XX.

Es así, que las mujeres de la tercera generación, pueden elegir no obedecer el destino reivindicador, purificador, que homologaba a la mujer con la Virgen María y la acercaba a la realización del ideal femenino. Sin embargo, roto este "vínculo espiritual con la feminidad", la nieta busca otro.

"Nieta: porque para mí ha sido un descubrir también eso. O sea no es algo que aprendí, más bien a mí, no sé creo que siempre fui libre. Digamos que si hubiera seguido mi línea normal hubiera aplicado ya un doctorado y seguiría estudiando ¿no? Pero no sé, me parece que hay ciertas cosas que hay que cambiar, creo que una mujer elija lo que elija no ha dejado de ser madre, y creo que por eso hay que reivindicar esa palabra, o sea el hecho de tener un útero, energéticamente lo que eso significa, es muy importante y hay muchas maneras de ser madre también ¿no? Entonces no sé” (nieta, entrevista grupal, 2013).

No se refiere a la maternidad biológica, que ya dejó en claro es una elección, justamente es una nueva negociación entre lo maternal y lo femenino, la nieta intenta responder los por qué y para qué, reflexiona sobre su lugar en el mundo, elige también qué tipo de madre, familia y mujer puede ser.

¿La reflexividad de la que habla Giddens? Propia de esta época y generación, el plantearse cómo y qué tipo de familia formar, ¿no es esto a lo que se refiere Beck y Beck-Gernsheim (2001) cuando habla de la negociación de las paternidades ${ }^{14}$ ? "Aunque de esta manera se despierten y desaten los demonios que duermen en todos los detalles" (Ibid.: 20), entonces nos enfrentamos a otra clase de ángeles y demonios, a otros ideales, glorias e infiernos, siendo así ¿no es este otro ethos?

\footnotetext{
"De manera que lo que un pueblo valora y lo que teme y odia están pintados en su cosmovisión, simbolizados en su religión y expresados en todo el estilo de vida de ese pueblo. Su ethos es distintivo, no sólo desde el punto de vista de la especie de excelencia que celebra, sino también desde el punto de vista de la clase de bajeza que condena; sus vicios son tan estilizados como sus virtudes" (Geertz, 1997: 122).
}

12 Stevens definió el marianismo como el opuesto complementario del machismo. Es decir, más que corresponder a una práctica religiosa, aunque esté conectado a una, el marianismo ha estado reflejado en la vida social en general, por cuanto afirmaba un tipo de identidad femenina. Cabe resaltar que fue un ideal de la mujer que prevaleció a lo largo del siglo XX- y que es posible persista.

"Marianismo is just as prevalent as machismo but it is less understood by Latin America themselves and almost unknown to foreigners. It is the cult of feminine spiritual superiority, which teaches that women are semi-divine, morally superior to and spiritually stronger than men" (Stevens, 1973: 91).

13 "La definición de la identidad femenina en función del ideal maternal es mistificadora en tanto esa respuesta impide la formulación de todo interrogante y ofrece la ilusión de ser que aliena al sujeto, encubriendo las carencias que harían posible el deseo" (Tubert, 2004: 114).

14 Dicho de otro modo y con referencia a nuestro campo temático: lo que es, significa, debería y podría ser la familia, el matrimonio, la paternidad, la sexualidad, el erotismo y el amor ya no puede ser presupuesto, preguntado o anunciado de forma obligatoria, sino que varía en cuanto a contenidos, delimitaciones, normas, moral y posibilidades incluso de individuo a individuo, de relación a relación, y tiene que ser descifrado, negociado, acordado y fundamentado en todos sus detalles del cómo, qué, por qué y por qué no, aunque de esta manera se despierten y desaten los demonios que duermen en todos los detalles (Beck y Beck-Gernsheim, 2001: 20). 
Un ethos donde no hay cabida para la mala $\mathrm{fe}^{15}$, ese desligamiento de la voluntad y libertad del sujeto del que habla Simone de Beauvoir (1999). ¿La ironía de la libertad impuesta? Las nuevas generaciones están constantemente sometidas a una construcción de narrativas propias ${ }^{16}$. Como señala Beck y Beck-Gernsheim (2001):

"La individualización significa justo el principio opuesto: la biografía del ser humano se desliga de los modelos y de las seguridades tradicionales, de los controles ajenos y de las leyes morales generales y, de manera abierta y como tarea, es adjudicada a la acción y a la decisión de cada individuo. La proporción de posibilidades de vida por principio inaccesibles a las decisiones disminuye, y las partes de la biografía abiertas a la decisión y a la autoconstrucción aumentan" (Ibid.: 19).

Aquí sostenemos que el mito, las representaciones, los discursos e interpretaciones son parte de un mismo universo semántico que es dinámico, construido culturalmente, siendo así, la experiencia y las relaciones se modifican conjuntamente. Se transforman las condiciones materiales, sociales y entonces también lo hacen los significados, o se recrean a partir de nuevos conceptos que designen lo concreto, y viceversa.

Entonces, cabe preguntarse si la familia, que es la principal unidad de reproducción de individuos y de organización de la producción en cualquier sistema social, ha cambiado ¿la organización económica del sistema capitalista-liberal, generó esta suerte de exigencias, empobrecimiento y a la vez libertades para las mujeres?

"Porque luchan contra la subyugación de las mujeres en la sociedad contemporánea, las feministas perciben la importancia central que la división sexual del trabajo tiene para el capitalismo en su empeño por dividir la fuerza de trabajo y obtener así salarios más bajos y un ejército de reserva de mano de obra (que se utiliza con especial eficacia para acabar con las habilidades y el poder de los artesanos) al mismo tiempo que obtiene un mantenimiento y una reproducción (física e ideológica) baratas de la fuerza de trabajo" (Davin en: Samuel, 1984: 265).

Porque hay que tomar en cuenta que el tener la potestad de dirigir la vida propia y sus circunstancias está atravesado por las posibilidades de la sujeta (en términos de las opciones concretas que tiene) frente a una estructura política, económica y legal que posiciona a las mujeres en oposición -y la mayoría de veces en desventaja- de los demás sujetos-masculinos ${ }^{17}$.

¿Qué sería si las abuelas y sus coetáneas no hubiesen pugnado por tener propiedad privada, salarios, puestos fijos, derechos laborales? Esta autonomía que, ciertamente, ellas pelearon por alcanzar y para la cual se necesitaron demandas concretas, que afectaron la vida diaria, pero que pueden a la vez reproducir el sistema que en primer lugar las precarizaba y subyugaba.

"No sé, a mi si me interesa retomar el tema de lo que es la familia y vivir en comunidad, o sea, me parece que la lucha nos ha dado libertad, pero también nos ha dado la libertad de escoger ser muy egoístas...Es que es una forma de desarrollo. Porque todo está basado en el sistema económico. Entonces eso es lo feo que en realidad nuestro progreso, muy aparte de todos estos procesos de liberación que hemos tenido, sobre todo las mujeres, creo que igual nos han llevado a una época donde igual no somos libres, porque ahora estamos atadas a un monstruo mayor que es el sistema capitalista, entonces de cierta manera ahorita solo somos agentes esclavos de un sistema que nos maneja" (nieta, entrevista grupal, 2013).

15 ...pero sería preciso entenderse sobre el alcance de la palabra ser; la mala fe consiste en darle un valor sustancial cuando tiene el sentido dinámico hegeliano: ser es haber devenido, es haber sido hecho tal y como uno se manifiesta; sí, las mujeres, en conjunto, son hoy inferiores a los hombres, es decir que su situación les ofrece menos posibilidades: el problema consiste en saber si semejante estado de cosas debe perpetuarse (Beauvoir, 1999: 26).

16 Que se evidencia a su vez en las historias de vida, cada acto y decisión es explicado, analizado, y construye para el presente un sentido.

17 Las estadísticas de tenencia de la tierra, bienes, cuentas bancarias, salarios por servicios profesionales, o aspiración laboral lo demuestran. Elementos que son en fin, la base concreta de la sociedad capitalista en la que vivimos; y que sin embargo, generan otro tipo de economías, y sobrevivencias. 
Es así, que la búsqueda de libertad de la sujeta responde, a su vez, a un proceso de modernización que ha generado individuas capaces de escoger y deliberar sobre los aspectos fundamentales de sus vidas como nunca antes en la historia; y que sin embargo, genera, un conflicto entre la representación de la mujer moderna (estudiada, trabajadora, intelectual, con ejercicio político, quizás hedonista y mundana también, completamente apropiada del espacio público) y la imagen de la mujer maternal -que la nieta justamente busca redefinir en el proceso histórico y cultural con el que negocia. Cabe señalar que la modernidad está repleta de mitos acerca de la libertad ${ }^{18}$, y en ésta se justifica de todo: desde el libre comercio hasta el libre albedrio ${ }^{19}$.

En fin, ¿cuál es la importancia de hablar acerca de lo que constituye lo femenino y lo maternal? ¿Por qué preguntarse qué es ser mujer? ¿Acaso a la hora de tomar decisiones nos detenemos a reflexionar cómo éstas afectan nuestra identidad?

Aunque no haya determinantes en la vida del individuo o individua, tendemos a pensar que hay situaciones, cosas, formas o relaciones sin las cuales no podríamos vivir, esto hace percibir el sistema como un conjunto cerrado, la cultura como una estructura hermética, no porque así sea, sino porque así la percibimos, es el truco del sentido común, ser incuestionable, naturalizar.

Que el discurso le dé sentido a la experiencia, también significa que de cierta manera este sentido, eso que aceptamos como certeza, donde asentamos una "verdad", que puede o no ser cuestionada, permite planificar, imaginar o prever el siguiente paso, es decir, el siguiente sentido, en fin seguir construyendo; y es esa la importancia de las representaciones.

La cuestión es captar cómo las prácticas, las rutinas, se ven modificadas por las representaciones, a través de esos minuciosos experimentos cotidianos, que como muestran los relatos de vida marcan la diferencia de una generación a otra ${ }^{20}$, y que operan a la par de grandes empresas y objetivos colectivos, porque están inscritos en el poder que ejerce cada estructura del sistema social en el que vivimos.

\begin{abstract}
"No, eso fue una época bien bonita, y full fiestas todo el tiempo, pero yo igual las fiestas... cuando estaba en colegio de monjas las fiestas igual eran con...chistosísimo porque se sentaba la abuelita, la tataraabuela, los tíos, los primos, las típicas fiestas pues, y te servían el pastelito, y te daban...de tomar no había, había colas o ponche, me acuerdo cuando yo estaba en primero o segundo curso, pero ya en cuarto curso en colegio mixto ahí si era, ya era otra cosa pues, el roncito y la cocacola...entonces para mí fue un despertar así bien, como que hubiera estado guardada del colegio de monjas al otro, entonces ahí si me destapé totalmente, paraba en fiestas todo el tiempo, tenía unas amiga que yo hacía mi maleta el día jueves y regresaba el domingo a mi casa, entonces pasaba en la casa de ellas, y eran fiesta, tras fiesta, tras fiesta. Y lo chévere era que los varones te pagaban todo, o sea no es como ahora, o sea una chica no necesitaba tener dinero" (madre, entrevista grupal, 2013).
\end{abstract}

\title{
Mujeres: cuerpos supervisados
}

En la estructura de familia patriarcal el padre tiene los derechos sobre la familia, la prole (que lleva su apellido), y los bienes conyugales de los cuales "su mujer" forma parte. A principios de siglo, él podía fijar la residencia, administrar los recursos de la pareja, y, aunque ante la ley el matrimonio se entienda como la asociación de dos personas iguales en derechos y deberes, las

18 Zerilli (2008) en el feminismo y el abismo de la libertad, cuando topa la cuestión del sujeto dice: "En opinión de Arendt, la preocupación exclusiva por el yo es una manifestación de la "alienación del mundo" característica de la modernidad" (Ibid.: 49).

19 "Las mujeres debemos trabajar, tener sobre nosotras las responsabilidades del trabajo, vivir sobriamente con nuestros propios recursos para ser libres y gozar del bien supremo de la libertad" (Vásconez, En: Goetschel, 2006: 329).

20 Las relaciones con pares del sexo opuesto eran sumamente escasas, simplemente porque no había espacios de encuentro aprobados, sin la tutela paterna. ¿Qué sensaciones producían los hombres en las mujeres? Me parece una pregunta interesante, ya que acostumbradas a la figura del padre y los hermanos pero no al relacionamiento abierto, amistad, solidaridad o entendimiento con el género masculino, más bien hay cierta clandestinidad y desconfianza en el encuentro con los otros para la generación más antigua. Que se vuelve un cambio importante para la segunda generación, con acceso a más espacios de socialización entre sexos. 
prácticas cotidianas -aún hoy en día- revelan una desigualdad profunda, que entre otras cosas otorga al hombre el derecho sobre el cuerpo femenino ${ }^{21}$.

Lo corpóreo es representado desde el acto que lo nombra, pero también como espacio político y estético; el cuerpo es el sitio primario para la construcción de un performance ${ }^{22}$. Las corporeidades están inmersas en diversos mecanismo de representación, entre los cuales constan las tecnologías generadas en un contexto histórico que forjan nuevas formas de relacionamiento, como la vestimenta, el maquillaje, las píldoras, inyecciones, avances médicos; y en el tema que nos compete la ginecología, diagnósticos de prevención y cuidado del embarazo, la madre y criatura, etc. Tecnologías que indudablemente han cambiado la historia de cómo las mujeres asumen la maternidad, y con esto la estructura familiar.

"Cuando las mujeres utilizan estos métodos, los hombres, por primera vez en la historia de la humanidad, ya no pueden exponerlas contra su voluntad al riesgo del embarazo, y su propio deseo de paternidad se vuelve así tributario de la voluntad de maternidad de sus parejas. Por lo demás, con los progresos de la genética, cada vez les resulta menos fácil no sólo descargar sobre su pareja la responsabilidad de su esterilidad (o de la no producción de varones), sino incluso continuar negando las paternidades que no quieres asumir" (Lefaucheur, en: Duby y Perrot, 1993: 65).

Así, aunque empezamos reflexionando sobre la construcción de las representaciones y las identificaciones, por estar inmersas en un entramado cultural, terminan necesariamente regresando nuestra mirada a la estructura del sistema, que se sustenta, entre otras cosas, en las condiciones precarias de trabajo de las mujeres, de lo doméstico y las relaciones íntimas. ¿Acaso construir relaciones con menos imposiciones, pesares, discursos sobre cómo, por qué, cuándo tener o no tener hijos, permitiría a su vez el desarrollo de una sensibilidad y conciencia comunitaria? "Ese vínculo materno es la base de una forma de la inteligencia humana no individual sino compartida, desarrollada en el permanente intercambio amoroso, en la ayuda mutua" (Aguirre, 2012: 32).

El cuidado de los niños y niñas, el abrazo, la ternura, la caricia y el acompañamiento no son considerados éxitos propios, y es que la maternidad ha sido considerada tan natural, obvia e incondicional que no se ha tomado en cuenta la transformación física, psicológica, vital que atraviesa la mujer.

No es sino, hasta la época actual que el mundo occidental, la ciencia, la psicología, el conocimiento en general, han regresado la mirada a la labor materna; a aquellas cosas que la sociedad industrial, moderna, no ha logrado remplazar: el afecto y presencia de la madre en la formación de la persona.

No es sino lógico crear un atmosfera de respeto y condiciones materiales que permitan a las mujeres elegir una maternidad placentera, y no se quede en el discurso de la feminidad idílica, que glorifica la maternidad y no hace sino justificar el poder que se ejerce sobre los cuerpos de las mujeres, como hemos visto de diferentes formas y con diversas representaciones, y su sometimiento en una sociedad profundamente desigual.

Para una infancia protegida que mantenga el vínculo con la madre, quizá mejores leyes laborales que atiendan la especificidad de la relación mujer-hija/o. Tal vez con esto las mujeres produzcan menos que su pares hombres, tal vez sin el estrés emocional de verse separada de sus hijos e hijas más, en cualquier caso ¿esa es una competencia en la que queremos entrar?

21 El castigo, el pudor, el desconocimiento hacen que la sexualidad y el placer estén caracterizados por el silencio. ¿Quién sabía acerca de la sexualidad? Se asume que los hombres son dueños del conocimiento acerca de las relaciones sexuales por su "naturaleza" masculina. ¿Es esto una expresión del conocimiento como herramienta de dominio, que convierte el acto sexual en una relación de poder?

22 La idea del performance sale de Andrade, X. Edema del Capitalismo Tardío. En:http://www.flacsoandes. org/antropologia_visual/index.php?option=com_content $\&$ view=article $\&$ id $=52$ : edema-del-capitalismotardio\&catid=47:ensayos-y-articulos\&Itemid=57. Accesado por última vez: Noviembre 19 del 2013. 


\section{Conclusiones}

El estudio del lenguaje, la semántica, mitos, discursos, y más específicamente de las representaciones permite mirar la estructura social en un proceso histórico donde se renueva, mostrando su dinámica, su capacidad de cambiar. Esto se debe a que teóricamente queda claro que las representaciones dan significado a la experiencia a través del lenguaje, y que funcionan como proceso y como producto. Al ser proceso ha demostrado hablar de un tiempo, del bagaje histórico, político donde se expresan diversas formas de representación e identificación, y al ser producto se ha expuesto situada, en este caso como experiencia urbana, emergiendo en un sistema donde se hace coherente, donde se naturaliza.

Este diálogo que hemos trazado nos dice que si bien es cierto que ha habido una pugna de las mujeres por apropiarse de esferas que se consideraban públicas, éstas constituyen parte de una misma organización social. Esto se debe a que -como mencionamos- hablar de lo público y privado es una separación histórica, más no estructural, y entonces aunque hemos analizado un proceso histórico, cambiante, dinámico, la transición de una forma de representación a otra ha estado condicionada de la capacidad de la estructura de transformarse y regenerarse.

En cuanto a las reflexiones acerca de la modernidad, sus instituciones y tecnologías, ciertamente han dado paso a la subjetividad y a la búsqueda de libertades individuales, que sin duda forman parte del proceso de auto-realización, independencia y elecciones que hoy en día marcan el panorama de las mujeres, sin embargo, esta perspectiva tiende a olvidar las resistencia, a subestimar el valor de lo colectivo donde realmente se teje la estructura social.

El sistema no es una estructura cerrada, conclusa, represiva. Si algo nos enseña las representaciones es que nosotros conformamos el sistema, porque somos quienes asocian las palabras, los discursos, los sentidos. De tal manera que, los seres humanos tenemos la capacidad infinita de cambiar las estructuras en que vivimos y entonces siempre podemos relacionarnos diferente.

También, se ha hecho evidente que las representaciones no existen únicamente en el discurso, en el habla, o si se quiere en palabras, modelan, transforman, las rutinas y prácticas. La representación abarca más que lo escrito o hablado, asume diversas formas del lenguaje, y en el caso sobre el que hemos reflexionado asume el cuerpo como primer espacio de construcción de un lenguaje.

Entonces, históricamente y estructuralmente el cuerpo de las mujeres ha estado vigilado por la potestad que han ejercido los hombres en su papel de padres de familia, jueces, jefes de instituciones, médicos, etc. Dando cuenta de una organización patriarcal contra la cual algunas mujeres han luchado, entre otras cosas, por la apropiación del propio cuerpo como acción política para la soberanía y como práctica ante un sistema que subordina y precariza sus condiciones vitales y de sus descendencias.

Finalmente, el devenir de la historia y la cultura, nos recuerda que los cambios no se dan únicamente con revoluciones populares, derrocamiento de gobiernos, levantamientos insurgentes, militantes y colectivos, sino que también ocurren en las relaciones más simples, en cada familia, con cada individuo, en toda historia. 


\section{Bibliografía}

Aguirre, Andrea. 2012, "El cultivo de nuestra memoria sensible: de la maternidad gozosa y poderosa", n. 4, Flor del Guanto, Quito, pp. 30-32.

Barthes, Roland. 2000, Mitologías, Siglo XXI, Madrid.

Beauvoir, Simone. 1999, El Segundo Sexo, editorial Sudamericana, Buenos Aires.

Beck, Ulrich y Beck-Gernsheim, Elisabeth. 2001, El normal caos del amor: las nuevas formas de la relación amorosa, Paidós. El Roure, Barcelona-Buenos Aires.

Davin, Anna. 1984, "Feminismo e historia del trabajo", en: Samuel Raphael, ed., Historia popular y teoría socialista, editorial Crítica, Barcelona, pp. 262-286.

Geertz, Clifford. 1997, La interpretación de las culturas, Gedisa, Barcelona.

Giddens, Anthony. 2000, La transformación de la intimidad. Sexualidad, amor y erotismo en las sociedades modernas, ediciones Cátedra, Madrid.

Goetschel, Ana María. 2001, "Educación e Imágenes de Mujer", en: Herrera, Gioconda (ed.), Antología de Género, FLACSO, Quito, pp. 339-352.

1999, Mujeres e Imaginarios: Quito en los inicios de la modernidad, Abya-Yala, Quito.

Hall, Stuart. 2003, “Introducción: ¿quién necesita identidad?”, en: Hall, Stuart, comp. Du Gay, Paul, (comp.), Cuestiones de identidad cultural, Amorrortu, Buenos Aires, pp. 13.

2000, "The work of representation", en: Hall, Stuart (ed.) Representation Cultural Representations and Signifying Practices, SAGE, The Open University, London, pp. 2-75.

Lefaucheur, Nadine. 1993, "Maternidad, familia, Estado", en: Duby, Georges; Perrot, Michelle, Historia de las mujeres, tomo 10, el siglo XX, la nueva mujer, Taurus, Grupo Santillana, Madrid.

Mato, Daniel. 2000, "Prácticas transnacionales, representaciones sociales y orientaciones de acción en la (re) organización de las "sociedades civiles" en América Latina, en: Mato Daniel, et. al. (coords.) América Latina en Tiempos de Globalización II: cultura y transformaciones sociales, UNESCO, pp. 73-91.

Stevens, Evelyn. 1973, "Marianismo: The Other Face of Machismo in Latin America", en: Pescatello, Ann (ed.), Female and Male In Latin America Essays, University of Pittsburgh Press, Pittsburgh, pp. 89-101.

Tubert Silvia. 2004, "La maternidad en el discurso de las nuevas tecnologías reproductivas", en: Osborne Raquel y De la Concha Ángeles (coords), Las mujeres y los niños primero: discursos sobre la maternidad, Icaria, España, pp. 111-138.

Zerilli, Linda. M. G. 2008, El Feminismo y el Abismo de la Libertad, Fondo de Cultura Económica, Buenos Aires, pp. 19-75. 